\title{
ANEDOTÁRIO COMO FERRAMENTA FACILITADORA NO PROCESSO DE AVALIAÇÃO ESCOLAR
}

\author{
Sabrina Monteiro ${ }^{1}$ \\ Luís Felipe Pissaia ${ }^{2}$
}

\begin{abstract}
Resumo: Este artigo trata de uma reflexão sobre aspectos relacionados à avaliaçáo em uma Escola Estadual de Ensino Fundamental localizada no Vale do Taquari, Rio Grande do Sul, Brasil. Objetivase analisar como o anedotário empregado por uma professora, favorece a construçáo de uma proposta de avaliaçáo para a aprendizagem. Dessa forma, faz-se essencial avaliar o aluno em todo o processo de aprendizagem. Para facilitar esse processo, propóe-se a utilização de um anedotário, que serve de apoio ao professor tanto nos registros e observaçóes, quanto no desempenho do aluno no seu processo de ensino e aprendizagem, em uma turma de quarto ano do Ensino Fundamental. Essa ferramenta pressupóe uma descrição breve de fatos importantes, significativos e relevantes ao processo, ou anotaçóes dos fatos observados, num determinado período de tempo, este sendo trimestral. Essa ferramenta também serve como facilitadora para a avaliação trimestral, chamada de parecer descritivo individual, necessário para a aprovação do aluno, em um contexto pedagógico escolar. Destaca-se que este trabalho desenvolveu-se a partir de pesquisas teóricas, visando a compreensão dos diferentes conceitos atribuídos, bem como seu papel no processo de ensino e aprendizagem vivenciado no contexto da sala de aula. Os dados obtidos para a realização desta análise, são provenientes de observaçóes e anotaçóes da professora em seu anedotário, durante o primeiro trimestre de 2017. Analisou-se como essa ferramenta auxilia a professora no acompanhamento do desenvolvimento do aluno, aspectos que precisam ser modificados para contemplar as dificuldades encontradas por eles, uma vez que, a avaliação utilizada enquadra-se na avaliação formativa, defendida por Bloom (1983). Sabe-se que náo existe uma concepção pronta para o processo avaliativo, mas avaliar antes de tudo, é um ato de investigação e de reflexão em que cada sujeito envolvido possa desenvolver da melhor forma o seu papel, visando, uma aprendizagem significativa, consistente e autônoma.
\end{abstract}

Palavras-chave: Avaliação. Anedotário. Parecer descritivo. Ensino e Aprendizagem.

1 Professora na Rede Estadual do RS. Mestranda no Programa de Pós Graduação Mestrado em Ensino - UNIVATES, contemplada com Taxa PROSUC/CAPES. sabrinamonteiro1991@gmail.com

2 Enfermeiro. Mestrando no Programa de Pós Graduação Mestrado em Ensino - UNIVATES. lpissaia@universo.univates.br 


\title{
ANEDOTÁRIO AS A FACILITATING TOOL IN THE SCHOOL EVALUATION PROCESS
}

\begin{abstract}
This article deals with a reflection on aspects related to evaluation in a State School of Primary Education located in Vale do Taquari, Rio Grande do Sul, Brazil. The objective is to analyze how the anecdotal employed by a teacher favors the construction of a proposal for evaluation for learning. It is assumed that the evaluation should contribute to reveal the identity of each student, while also preserving the plurality of opinions that constitute any school. In this way, it is essential to evaluate the student in the whole learning process. In order to facilitate this process, it is proposed to use an anecdote, which serves as support to the teacher both in the registers and observations, and in the performance of the student in his teaching and learning process, in a fourth year class of Elementary School. This tool assumes a brief description of important, significant and relevant facts to the process, or notes of the observed facts, in a certain period of time, this being quarterly. This tool also serves as a facilitator for the quarterly evaluation, called the individual descriptive opinion, necessary for student approval, in a pedagogical school context. It is noteworthy that this work was developed from theoretical research, aiming at understanding the different concepts attributed, as well as its role in the teaching and learning process experienced in the context of the classroom. The data obtained to carry out this analysis come from observations and notes of the teacher in her anecdote during the first quarter of 2017. It was analyzed how this tool helps the teacher to follow the development of the student, aspects that need to be modified to to consider the difficulties encountered by them, since the evaluation used is part of the formative evaluation, defended by Bloom (1983). It is known that there is no ready recipe for the evaluative process, but to evaluate first of all, it is an act of investigation and reflection in which each involved subject can develop in the best possible way its role, aiming at a meaningful, consistent learning and autonomous.
\end{abstract}

Keywords: Evaluation. Anedotário. Descriptive Opinion. Teaching and learning.

\section{INTRODUÇÃO}

Este artigo é decorrente de alguns questionamentos emergentes sobre a indissociabilidade entre a avaliação e a aprendizagem dos alunos. Partiu-se do pressuposto que os instrumentos de avaliação não podem ser pensados como um recurso para mensurar a aprendizagem, mas sim integrar um processo pedagógico que visa fomentá-la. Visto isso, destaca-se que este texto possui um caráter reflexivo, e nele busca-se analisar como os anedotários empregados por uma professora, favorecem a construção de uma proposta de avaliação para a aprendizagem. O trabalho realizou-se em uma Escola Estadual localizada na periferia do Vale do Taquari, Rio Grande do Sul, Brasil, sendo que a avaliação adotada pela instituição é em formato temporal trimestral, realizada por meio de um parecer descritivo e como forma de facilitar o registro, a professora utiliza um anedotário.

No mundo contemporâneo o processo de avaliar necessita ser uma prática constante, porém, não é uma tarefa fácil. Para Sant'Anna (1995, p. 29-30) a avaliação é "“...] um processo pelo qual se procura identificar, aferir, investigar e analisar as modificações do comportamento e rendimento do aluno, do educador, do sistema, confirmando se a construção do conhecimento se processou, seja este teórico (mental) ou prático". Para o autor, avaliar é ter outro olhar entre os sujeitos 
da instituição escolar, considerando o meio em que os atores estão inseridos, sua realidade para minimizar as dificuldades encontradas na aprendizagem.

Partindo dessas considerações, Demo (2002, p. 29) complementa que “[...] a avaliação para a aprendizagem é procedimento fundamental, indispensável e permanente, seja no sentido do diagnóstico sempre atualizado, seja no sentido da intervenção apropriada". Nessa perspectiva, faz-se necessário acompanhar todo o processo de aprendizagem, por conseguinte, o instrumento aqui descrito é o anedotário. Este consiste em um caderno de anotações, no qual os professores podem descrever de modo breve fatos importantes, significativos e relevantes ao processo de ensino, ou anotações dos fatos observados, num determinado período de tempo. Dessa forma, o professor atenta-se para situações ou acontecimentos que sirvam para sua reflexão ou tomada de decisão. As anotações podem ser referentes a um aluno em particular para acompanhamento da evolução da sua aprendizagem ou para demais situações cotidianas da sala de aula.

Este estudo está organizado em quatro seções. Na primeira delas, denominada "Funções da Avaliação: Diagnóstica, Formativa e Somativa" aborda-se aspectos alusivos ao referencial teórico quanto a função da avaliação no ambiente escolar. $\mathrm{Na}$ segunda seção "Contexto em estudo" apresenta-se uma breve caracterização da escola e do meio onde está situada. Em seguida, descreve-se o "Anedotário como instrumento de avaliação" nas práticas avaliativas de uma professora e da forma como este instrumento pode constituir uma ferramenta facilitadora de acompanhamento da aprendizagem do aluno. E por fim, faz-se as considerações finais.

\section{FUNÇÓES DA AVALIAÇÁO: DIAGNÓSTICA, FORMATIVA E SOMATIVA}

A avaliação é um processo que envolve investigação, reflexão, intervenção e interação em que cada sujeito consiga desenvolver da melhor forma o seu papel, objetivando-se que alcance uma aprendizagem significativa, consistente e autônoma. Cabe salientar que esse processo é permanente, constante e necessita de alterações conforme o cenário das atuais necessidades. Conforme Bloom (1983) a avaliação escolar é classificada em três grandes grupos: avaliação diagnóstica, formativa e somativa. Partindo desse pressuposto, Kraemer (2010) destaca que a avaliação diagnóstica pretende averiguar a posição do aluno face a novas aprendizagens que lhe vão ser propostas e a aprendizagens anteriores que servem de base àquelas, no sentido de obviar as dificuldades futuras e, em certos casos, de resolver situações presentes. Em consonância, Luckesi (2000, p. 09) complementa que "[...] para avaliar, o primeiro ato básico é o de diagnosticar, que implica, como seu primeiro passo, coletar dados relevantes, que configurem o estado de aprendizagem do educando ou dos educandos". Da mesma forma:

A avaliação diagnóstica é aquela realizada no início de um curso, período letivo ou unidade de ensino, com a intenção de constatar se os alunos apresentam ou não o domínio dos pré-requisitos necessários, isto é, se possuem os conhecimentos e habilidades imprescindíveis para as novas aprendizagens. É 
também utilizada para caracterizar eventuais problemas de aprendizagem e identificar suas possíveis causas, numa tentativa de saná-los (HAYDT, 1988, p. 16-17).

Nessa mesma perspectiva Jorba e Sanmartí (2003, p. 27), evidenciam que a avaliação diagnóstica, também chamada de avaliação inicial, “[...] tem como principal objetivo determinar a situação de cada aluno antes de iniciar um determinado processo de ensino e aprendizagem, para poder adaptá-lo a suas necessidades". Acredita-se que o professor através deste diagnóstico inicial, usualmente conhecido como concepções prévias ou ideias prévias, consegue identificar após um determinado tempo a evolução da sua aprendizagem.

Os alunos apresentam diferentes ritmos de aprendizagem, em decorrência das suas especificidades, além disso é perceptível que alguns possuem mais dificuldade em compreender, enquanto outros esquecem mais rapidamente o conteúdo. É por meio dessa avaliação inicial, com função diagnóstica, “[...] que o professor vai determinar quais os conhecimentos e habilidades devem ser retomados, antes de introduzir os conteúdos programáticos específicos" (HAYDT, 1988, p. 20). Nessa mesma perspectiva, Alvarenga (2002) atenta para a necessidade de que os conhecimentos prévios dos alunos, sejam objeto de avaliação para poder integrar os conhecimentos pretendidos e então verificar se houve aprendizagem. Dessa forma, destaca-se que a partir deste diagnóstico, o professor pode fazer o acompanhamento de quanto conseguiu evoluir desde a sua concepção inicial, ou se ainda não atingiu o que foi proposto e precisa ser retomado. Alvarenga (2002, p. 13) complementa bem essas colocações e salienta a importância de levar em consideração as concepções prévias

[...] descobrir que bagagem os alunos trazem, seus conceitos espontâneos e científicos, esquemas de aprendizagem, formas como resolvem problemas, fatores atitudinais, motivacionais e afetivos, curiosidade, estilo cognitivo, crenças, torna-se importante para proposição de atividades de aprendizagem dos conteúdos a serem ensinados.

Outra função da avaliação para a aprendizagem, destacada por Bloom (1983), é a função formativa, a qual preocupa-se em acompanhar o desempenho do aluno. Para Kraemer (2010) através desta, identifica-se as dificuldades que o aluno apresenta para que, seja possível oportunizar situações para aprender o que ainda não conseguiu. Objetiva-se repensar uma proposta que oportunize a aprendizagem do aluno, contribuindo assim para fornecer dados para aperfeiçoar o processo, verificando se os objetivos foram ou não atingidos.

Na visão de Hadji (2001, p. 20), a partir do momento que informa, a avaliação é formativa. A avaliação torna-se formativa na medida em que "[...] se inscreve em um projeto educativo específico, e que favoreça o desenvolvimento daquele que aprende, deixando de lado qualquer outra preocupação". Acredita-se que uma avaliação formativa auxilia o professor a informar o andamento de seu trabalho, para que poderá fazer as devidas regulamentações das suas ações. Já para o aluno, 
esse tipo de avaliação, permite evidenciar o seu desempenho e tomar consciência das dificuldades que encontra no seu processo de aprendizagem.

Segundo Rabelo (1998, p. 73), uma avaliação formativa tem a finalidade de "[...] proporcionar informações acerca do desenvolvimento de um processo de ensino e aprendizagem". Partindo desse pressuposto, entre suas principais funções estão, as de apoiar e orientar os alunos, uma vez que "[...] é uma avaliação incorporada no ato do ensino e integrada na ação de formação" (RABELO, 1998, p. 73). Nesta perspectiva, o autor destaca que essa avaliação contribui para melhorar a aprendizagem, pois auxilia o professor a verificar as melhorias necessárias para que o aluno possa avançar, o que precisa ser ajustado como forma de contribuir no processo de aprendizagem.

A outra função da avaliação é a somativa, que por sua vez, Kraemer (2010, p. 4), destaca que "[...] pretende ajuizar do progresso realizado pelo aluno no final de uma unidade de aprendizagem, no sentido de aferir resultados já colhidos por avaliações do tipo formativa e obter indicadores que permitem aperfeiçoar o processo de ensino". A avaliação somativa acontece no final do processo de ensino, serve para verificar o que o aluno aprendeu depois de todo conteúdo trabalhado pelo professor, dessa forma, são atribuídas notas que serão divulgadas posteriormente. Nesta mesma perspectiva, Haydt (1988, p. 18) explica que:

[...] a avaliação somativa, com função classificatória, realiza-se ao final de um curso, período letivo ou unidade de ensino, e consiste em classificar os alunos de acordo com níveis de aproveitamento previamente estabelecidos, geralmente tendo em vista sua promoção de uma série para outra, ou de um grau para outro.

Acredita-se que, os professores não devem utilizar a avaliação apenas como instrumento de classificação, pois não leva em consideração todo o crescimento e desenvolvimento do aluno. Dessa forma, Luckesi (2002, p. 77), evidencia que "[...] a prática classificatória da avaliação é antidemocrática, uma vez que não encaminha uma tomada de decisão para o avanço e crescimento", assim sendo, ela tem função apenas de classificação. Partindo desse pressuposto, Rabelo (1998), complementa que não tem sentido a escola continuar usando notas classificatórias, acredita-se que a avaliação apenas como instrumento com essa finalidade não auxilia o aluno no seu crescimento e desenvolvimento, pois ela apenas atribui uma nota ou um conceito, sem levar em consideração todo o processo de aprendizagem.

\section{CONTEXTO EM ESTUDO}

Este estudo pretende analisar a utilização de um anedotário na construção de uma proposta de avaliação para a aprendizagem. Para isso, os sujeitos envolvidos, foram um grupo de dezoito crianças, entre nove a treze anos, que frequentam o quarto ano do Ensino Fundamental, sendo doze meninos e seis meninas, na qual a autora é docente. A escola onde este estudo foi realizado, localiza-se em um bairro de periferia de classe baixa do Vale do Taquari, Rio Grande do Sul, Brasil, possuindo 
um contexto social marcado pelos altos índices de criminalidade e frequentemente, conflitos de violência física e verbal ocorrem no ambiente escolar.

No início do ano letivo foi perceptível que muitos alunos não envolviam-se nas atividades que eram propostas. Em consonância com Fita (1999, p.77) “[...] a motivação é um conjunto de variáveis que ativam a conduta e a orientam em determinado sentido para poder alcançar um objetivo". Também nos dias atuais, o tema motivação está relacionado à aprendizagem, mas não se restringe somente a ela, pois conforme Bzuneck, (2001, p.10) "[...] na vida humana existe uma infinidade de áreas diferentes e o assunto da motivação deve contemplar suas especificidades".

Na mesma perspectiva, Barbosa (2005) destaca que ao observar-se o porquê das pessoas serem motivadas, deve-se levar em consideração dois fatores: o fator intrínseco, que é a vontade da própria pessoa, e o fator extrínseco, que é ocasionada por fatos externos principalmente do ambiente de trabalho. À vista disso, verificase que a motivação é um comportamento causado por necessidades, direcionado aos objetivos de satisfação desses indivíduos.

A professora envolvida nesta pesquisa, desde o início do ano de 2017 sentia-se aflita, pois seus alunos relatavam a falta de expectativas pelo futuro, desacreditados em seu potencial, mesmo estando no quarto ano do Ensino Fundamental. Pérez Gómez (2015, p.35) reflete sobre esse aspecto e destaca que "[...] é óbvio que os ambientes menos favorecidos do ponto de vista econômico, social e cultural incentivam atitudes e expectativas menores com relação à escola e ao estudo". Assim sendo, cabe ao professor a tarefa de refletir sobre a sua prática, identificando as necessidades, os desafios da sociedade contemporânea, as inquietações vindas dos alunos e, a partir disso, criar estratégias de ensino para os conteúdos que realmente atribuam significado na vida deles. Nóvoa (2009) corrobora com essa afirmação ao salientar que a contemporaneidade exige dos professores grande capacidade de contextualizar a escola para que ela assuma seu papel social e, assim, valorizar aquilo que é de sua competência, o saber e a formação humana.

Os dados obtidos para a realização desta análise, foram provenientes das observações e anotações da professora em seu anedotário, durante o primeiro trimestre de 2017. Analisou-se como essa ferramenta auxilia a professora no acompanhamento do desenvolvimento do aluno, pois através dele é possível verificar aspectos que precisam ser modificados para contemplar as dificuldades encontradas por eles.

\section{ANEDOTÁRIO COMO INSTRUMENTO DE AVALIAÇÁO}

Nesta seção do artigo discute-se os dados obtidos por meio das práticas profissionais realizadas com as crianças. Parte-se do pressuposto que o anedotário consiste em um conjunto de notas, nos quais os professores podem descrever de modo breve fatos importantes, significativos e relevantes ao processo diário de sala de aula, ou anotações dos fatos observados, num determinado período de tempo. Dessa forma, o professor precisa voltar-se para situações ou acontecimentos que sirvam para sua reflexão ou tomada de decisão. Alvarez Méndez (2002) destaca que 
ao utilizar a observação como instrumento é importante delimitar e estabelecer seus campos, isto é, dada a complexidade e quantidade de fenômenos que ocorrem de modo concomitante no espaço de sala de aula, cabe ao docente, por meio de uma escuta sensível, registrar os episódios que são atribuídos aos dados observados e qual o papel dos sujeitos no processo. Alvarenga (2002, p. 15), nessa mesma perspectiva, destaca que:

Os instrumentos - portfólio, check-lists, anedotários - são úteis quando bem elaborados e asseguram a reutilização dos dados como guia para o ensino, assim como instrumento para auto-avaliação. A partir dessas informações, o processo de ensino e aprendizagem pode ser desencadeado permitindo a apropriação e elaboração, além de exigir que o sujeito pense sobre os próprios conceitos.

Ressalta-se que o foco do registro das observações deve pautar-se na aprendizagem do aluno e não nos aspectos comportamentais, exceto os fatos que incorram no processo de ensino e aprendizagem. Nessa avaliação é feito um diagnóstico e considerações referentes a aprendizagem durante o período, apontando meios para a superação das dificuldades a fim de facilitar a interação dos conteúdos curriculares e seu cotidiano. Também consta neste documento, conteúdos e projetos desenvolvidos, vinculados com a proposta pedagógica da escola. Partindo desse pressuposto, o instrumento em destaque, serve também de apoio para que ao final de cada trimestre seja feita a avaliação trimestral, chamada de "Caminhada de Turma", adotada pela instituição no qual é feito o estudo. Como análise, verificou-se alguns excertos:

A turma do $4 .^{\circ}$ ano 2 é composta por dezoito alunos, sendo seis meninas e doze meninos. É uma turma muito criativa e dinâmica, na maioria das vezes recebem bem as atividades propostas pela professora. A produção escrita e leitura foram bastante enfatizadas neste trimestre. Quanto à produção escrita foram explorados diferentes gêneros textuais e construção de frases. O estudo dos sinais de pontuação, do vocabulário, uso do dicionário, encontros vocálicos, substantivos próprios e comuns, singular e plural e da ortografia foram conteúdos trabalhados para a qualificação na escrita textual.

Através de problemas matemáticos, realizou-se diversos cálculos relembrando e enfatizando as quatro operações e as leis do um a cinco, as quais alguns alunos ainda apresentam maior dificuldade. Introduziu-se também o conceito de números antecessores e sucessores, bem como também enfatizou-se os números decimais, explorando unidades, dezenas, centenas e milhares. Gradativamente, foi propondo-se atividades as quais proporcionaram a busca de soluções de problemas, fazendo assim com que eles se envolvessem e motivassem cada vez mais, no sentido de construir o conhecimento matemático. Nessa perspectiva, tiveram a oportunidade de aprofundar seu conhecimento matemático através de resolução e redação de soluções de problemas, leitura e interpretação de textos matemáticos, explorando também as operações inversas, através da resolução da prova real das operações.

Sugere-se que seja reforçado com todos os alunos a importância do respeito com o outro, pois as normas de convivência e autocontrole são essenciais para o bom convívio. É importante ressaltar sobre a concentração que é fundamental durante a aula, não conversar sobre o que não for referente a 
esta, cuidando para não dispersar-se, o que acaba atrasando andamento e realização das atividades, consequentemente prejudicado a aprendizagem de cada um.

Conforme analisou-se no excerto, percebe-se que a professora relata alguns conteúdos trabalhados no decorrer do trimestre, apontando situações que precisam ser retomadas, onde alguns alunos ainda apresentam dificuldade, como é o caso das leis matemáticas do um ao cinco. Acredita-se que, conforme Bloom (1983), esse é o tipo de avaliação formativa, pois ela preocupa-se em acompanhar o processo de desenvolvimento de aprendizagem do aluno. Ressalta-se a importância do anedotário no cotidiano escolar, pois ele proporciona um método interessante de acompanhamento da aprendizagem dos alunos, pois é possível monitorar seu crescimento e também se houve algum retrocesso. Abaixo é descrito um excerto de parecer individual trimestral construído pela professora do quarto ano, necessário para a aprovação do aluno, em um contexto pedagógico escolar:

Com base nas avaliações realizadas e no desempenho da aluna em sala de aula durante o primeiro trimestre, foi possível constatar que a aluna mostra interesse na realização das atividades e é muito solícita. Participa das aulas atentamente, tira sus dúvidas, faz colocações, interagindo com o grupo e com a professora. Nas aulas realiza as atividades propostas com dedicação, empenho e agilidade. Apesar de apresentar uma certa dificuldade em algumas atividades, principalmente nas que envolvem interpretação e escrita, sempre dedica-se e procura ajuda para conseguir realizá-la. Tem um bom raciocínio lógico-matemático, apresentando agilidade na realização das atividades que apresentam investigação matemática. Sua organização pessoal e seu caderno são exemplares [...].

Analisando o parecer descrito acima, foi possível identificar novamente a avaliação formativa, enfatizada por Bloom (1983). Há uma breve descrição de como a aluna está evoluindo, destaca-se que é empenhada, participativa e que tem um bom raciocínio lógico-matemático, mas também há uma preocupação em destacar que apresenta dificuldade em atividades de interpretação e escrita.

Partindo da análise do anedotário utilizado pela professora, constatou-se que ele serve como forma facilitadora de acompanhamento do desenvolvimento do aluno. Para a utilização deste instrumento, não há um modelo específico para essas anotações. Cabe ao professor, construir um modelo próprio com base nos objetivos, conteúdo trabalhado e forma de trabalho realizado em sala de aula. Assim, pode ser utilizado um caderno de anotações ou outra forma previamente preparada para isso. A professora adotou a utilização de um anedotário organizado em forma de fichas, contendo fotos dos alunos e suas anotações que merecem destaque, ou de forma semanal, com as respectivas datas, analisando aspectos previamente selecionados por ela, como leitura, escrita, acompanhamento das atividades do caderno. Assim sendo, analisou-se algumas das anotações da professora:

No dia 15 de março, verificou-se a não compreensão das letras em script do aluno $\mathrm{M}$, apenas em formato palito. 
No dia 22 de março, o aluno E conseguiu pela primeira vez realizar sozinho cálculos de subtração envolvendo empréstimos.

No dia 19 de abril, constatou-se que a aluna M ainda não está alfabetizada, está no nível silábico. E a escrita de diversas letras ainda está em formato espelhado.

No dia 28 de abril, os alunos E e M, mostraram-se muito resistentes em participar de uma atividade lúdica no pátio, envolvendo cantigas e rodas cantadas, alegavam que não queriam participar com os colegas e brincar com os colegas. Estes dois alunos, não interagem com os colegas nas mais diversas situações, sejam dentro ou fora da sala de aula, isso é preocupante, pois a socialização é fundamental para o bom convívio.

No dia 5 de maio, observou-se que o aluno $G$ demostra uma certa teimosia quanto o cumprimento de algum combinado, isso deve ser trabalhado, pois são essenciais para a bom convivência humana. Ele é extremamente resistente quando contrariado, nega-se e chora quando precisa mudar sua postura e seguir alguma norma previamente acordada no grupo.

No dia 24 de maio, observou-se que a aluna $\mathrm{E}$ precisa ter um pouco mais de atenção durante a aula, cuidando para não dispersar-se e preocupar-se com o que os colegas estão fazendo, o que acaba atrasando andamento e realização das atividades, por isso seu caderno está incompleto. A aluna deve dedicar-se mais nos estudos, treinar mais na matemática e a leitura.

No dia 28 de maio, constatou-se que os alunos G e L estão demonstrando um excelente desempenho nas atividades propostas, as quais estão sendo realizadas em duplas.

No dia 29 de maio, a aluna A pela primeira vez conseguiu ler em voz alta trechos de um livro que retirou da biblioteca.

Partindo da análise realizada, foi perceptível a preocupação da professora, em fazer os registros e acompanhamento do processo de aprendizagem dos alunos. Percebe-se que as anotações descrevem o desenvolvimento, como situação da evolução da letra de forma para a cursiva e também do cálculo de subtração envolvendo empréstimos. Cabe destacar também que, através das anotações, é possível identificar que tem uma aluna no quarto ano ainda não alfabetizada, por isso esse tipo de avaliação é a destacada por Bloom (1983), como formativa, pois ela oportuniza o acompanhamento do desenvolvimento do processo do aluno e a partir disso, o professor consegue desenvolver meios que possibilitem o aluno a superar suas dificuldades.

Como forma de continuidade de trabalho, a professora acompanha o desempenho dos envolvidos através de observações e reflexões partindo das atividades desenvolvidas, e faz as suas considerações em um anedotário. Esses dados favorecem o aperfeiçoamento do processo de ensino e aprendizagem, verificando se os objetivos foram ou não atingidos, como por exemplo na anotação do dia 29 de maio, onde destaca-se que a aluna A conseguiu ler em voz alta alguns trechos do livro retirado, percebe-se que houve um acompanhamento da professora até que ela conseguisse ler o trecho. Este tipo de acompanhamento por sua vez, também assume um caráter de avaliação formativa, onde evidencia-se uma preocupação em saber o que o aluno atingiu, em termos de conteúdo esperado e o que ainda 
necessita ser mais trabalhado e acompanhado. Assim sendo, percebe-se que ela adota uma avaliação de forma constante, valorizando todas as atividades realizadas de forma diária.

\section{CONSIDERAÇÓES FINAIS}

A avaliação tem sido considerada por muito tempo, como um instrumento que ocorre somente ao final do processo de ensino e aprendizagem. Mas com as constantes mudanças, culturais, sociais e escolares, percebeu-se que isso não era o suficiente. Consequentemente, a avaliação para a aprendizagem, passou a ser adotada em todo processo de ensino e aprendizagem. Foi perceptível a preocupação da professora em fazer os registros do processo de ensino, no qual envolveu as diversas atividades com interpretações, raciocínio-lógico, orais ou escritas. Os resultados destas, por sua vez, são descritos no seu anedotário, destacando-se como esse instrumento atua facilitando e contribuindo no acompanhamento do processo evolutivo do aluno.

É evidente que não existe uma receita pronta para o processo avaliativo, mas avaliar antes de tudo, é um ato de investigação e de reflexão em que cada sujeito envolvido possa desenvolver da melhor forma possível o seu papel, visando, uma aprendizagem significativa, consistente e autônoma. Partindo desse pressuposto, o processo avaliativo permite diagnosticar as dificuldades encontradas no processo de aprendizagem de forma que se considere o contexto escolar como um todo. Dessa forma, a professora envolvida procura avaliar o aluno em sua totalidade, de forma diária, assim o anedotário torna-se uma ferramenta que auxilia muito na sua prática diária, pois através dele é possível identificar objetivos que o aluno já conquistou e aspectos que devem ser explorados, ou seja, permite o professor acompanhar o progresso de construção do conhecimento.

\section{REFERÊNCIAS}

ALVARENGA, G. M. Avaliação: o olhar dos alunos. In: ALVARENGA, G. M. (org). Avaliação: o saber na transformação do fazer. Londrina: Núcleo de Estudos e Pesquisas em Avaliação Educacional, Editora da UEL, 2002.

BARBOSA, D. F. Motivação no Trabalho, Revista de Ciências Empresariais, v. 2, n.1, p. 20-25, jan./jun. 2005.

BLOOM, B. S. et. al. Manual de avaliação formativa e somativa do aprendizado escolar. São Paulo: Livraria Pioneira Editora, 1983.

BZUNECK, J. A. A motivação do aluno: aspectos introdutórios. In:

BORUCHOVITCH; José Aloyseo. BZUNECK. A motivação do aluno. Contribuições à Psicologia Contemporânea. Petrópolis: Vozes, 2001. p. 09-36.

DEMO, P. Complexidade e aprendizagem: a dinâmica não linear do conhecimento.

São Paulo: Atlas, 2002. 
FITA, E. C. O professor e a motivação dos alunos. In: TAPIA, J. A.; FITA, E. C. A motivação em sala de aula: o que é, como se faz. 4. ed. São Paulo: Loyola, 1999. p. 65-135.

HADJI, C. Avaliação desmistificada. Porto Alegre: Art Med, 2001.

HAYDT, R. C. C. Avaliação do processo ensino-aprendizagem. São Paulo: Ática, 1988.

JORBA, J.; SANMARTÍ, N. A função pedagógica da avaliação. In: BALLESTER, M. et al. Avaliação como apoio à aprendizagem. Porto Alegre: Artmed, 2003.

KRAEMER, M. E. P. A Avaliação Da Aprendizagem Como Processo

Construtivo De Um Novo Fazer. Disponível em < http:/ /www.ufvjm.edu.br/site/ educacaoemquimica/files/2010/11/Avaliacao-ComoProcesso-de-Construcao.pdf $>$ acesso: $26 / 06 / 2017$

LUCKESI, C. C. O que é mesmo o ato de avaliar a aprendizagem? Pátio, Rio Grande do Sul, n.12, p. 6-11, fev/mar. 2000.

Avaliação da aprendizagem escolar. São Paulo: Cortez, 2002.

MÉNDEZ, J. M. A. Avaliar para conhecer, examinar para excluir. Porto Alegre: Artmed, 2002.

NÓVOA, A. Para uma formação de professores construída dentro da profissão. In: . Professores: imagens do futuro presente. Lisboa: Educa, 2009. p. 25-46.

PÉREZ GÓMEZ, A. L. Educação na era digital: a escola educativa. Porto Alegre: Penso, 2015. 192p.

RABELO, E. H. Avaliação: novos tempos e novas práticas. Petrópolis, RJ: Vozes, 1998.

SANT'ANNA, I. M. Por que avaliar? Como avaliar? Critérios e instrumentos. $3^{\text {a }}$ Edição, Petrópolis, RJ: Vozes, 1995. 